Georgia State University

ScholarWorks @ Georgia State University

$11-28-2012$

\title{
Inhalation Therapy in Patients Receiving Mechanical Ventilation: An Update
}

Arzu Ari

Georgia State University, aari1@gsu.edu

James B. Fink

Georgia State University, jfink@gsu.edu

Rajiv Dhand

University of Tenn, rdhand@uthsc.edu

Follow this and additional works at: https://scholarworks.gsu.edu/rt_facpub

Part of the Respiratory System Commons

\section{Recommended Citation}

Arzu Ari, James B. Fink, and Rajiv Dhand. Journal of Aerosol Medicine and Pulmonary Drug Delivery. December 2012, 25(6): 319-332. doi:10.1089/jamp.2011.0936.

This Article is brought to you for free and open access by the Department of Respiratory Therapy at ScholarWorks @ Georgia State University. It has been accepted for inclusion in Respiratory Therapy Faculty Publications by an authorized administrator of ScholarWorks @ Georgia State University. For more information, please contact scholarworks@gsu.edu. 


\title{
Inhalation Therapy in Patients Receiving Mechanical Ventilation: An Update
}

\author{
Arzu Ari, Ph.D., R.R.T., FAARC,1 James B. Fink, Ph.D., R.R.T., FAARC, \\ and Rajiv Dhand, M.D., FACP, FCCP, FAARC ${ }^{2}$
}

\begin{abstract}
Incremental gains in understanding the influence of various factors on aerosol delivery in concert with technological advancements over the past 2 decades have fueled an ever burgeoning literature on aerosol therapy during mechanical ventilation. In-line use of pressurized metered-dose inhalers (pMDIs) and nebulizers is influenced by a host of factors, some of which are unique to ventilator-supported patients. This article reviews the impact of various factors on aerosol delivery with pMDIs and nebulizers, and elucidates the correlation between in-vitro estimates and in-vivo measurement of aerosol deposition in the lung. Aerosolized bronchodilator therapy with pMDIs and nebulizers is commonly employed in intensive care units (ICUs), and bronchodilators are among the most frequently used therapies in mechanically ventilated patients. The use of inhaled bronchodilators is not restricted to mechanically ventilated patients with chronic obstructive pulmonary disease (COPD) and asthma, as they are routinely employed in other ventilator-dependent patients without confirmed airflow obstruction. The efficacy and safety of bronchodilator therapy has generated a great deal of interest in employing other inhaled therapies, such as surfactant, antibiotics, prostacyclins, diuretics, anticoagulants and mucoactive agents, among others, in attempts to improve outcomes in critically ill ICU patients receiving mechanical ventilation.
\end{abstract}

Key words: aerosols, nebulizers, metered-dose inhalers, mechanical ventilation

\section{Introduction}

$\mathbf{I}^{2}$ $\mathbf{N}$ THE 1980s, there was a widely prevalent opinion that aerosolized therapies were unlikely to be successful in mechanically ventilated patients because of the extremely poor efficiency of drug delivery in this setting.(1) Many barriers, especially the inability of drug particles to negotiate the ventilator circuit and endotracheal tube, were thought to preclude effective aerosol delivery to ventilator-supported patients, and this view was supported by landmark studies that corroborated the low pulmonary deposition of aerosolized drugs in this patient population compared to ambulatory, nonintubated patients. ${ }^{(2)}$ In the past, the poor efficiency of aerosol-generating devices in ventilator circuits, inadequate understanding of the factors influencing aerosol delivery during mechanical ventilation, and older generation mechanical ventilators that were not designed for aerosol use posed major impediments to effective drug delivery. The successful transformation to a higher efficiency of aerosol delivery is due to the efforts of several investigators who have collectively helped to clarify the optimal techniques for inhalation therapy during mechanical ventilation. This article updates the literature on inhalation therapy and discusses the appropriate methods to employ for administration of inhaled drugs in adult ventilator-supported patients.

Adequate amounts of the drug need to deposit in the lung to produce clinical effects. ${ }^{(3)}$ The amount of drug delivered to the lower respiratory tract can be predicted on the basis of bench models of mechanical ventilation that simulate the clinical setting. ${ }^{(4)}$ With pressurized metered-dose inhalers (pMDIs), the drug output per actuation is already defined, and several elegantly performed in vitro studies permit fairly precise prediction of drug deposition in the lung. ${ }^{(5,6)}$ The amount of drug delivered to the lung with a nebulizer can also be estimated under specified conditions of nebulizer operation so that the time required to deliver a known

\footnotetext{
${ }^{1}$ Georgia State University, Division of Respiratory Therapy, Atlanta, Georgia.

${ }^{2}$ Professor and Chairman, Department of Medicine, University of Tennessee Graduate School of Medicine, Knoxville, Tennessee.

Presented at ISAM Congress 2011 Rotterdam.
} 
amount of drug can be accurately estimated. ${ }^{(7)}$ Therefore, the ability to control circuit conditions, ventilatory parameters, and conditions of nebulization allows estimation of drug delivery with a range of nebulizers that differ in their operational efficiency. In addition to the total amount of drug delivered, the precision, reliability, and consistency of dosing are important factors that influence the response to treatment. ${ }^{(3,4)}$ Adequate understanding of the factors governing lung deposition of aerosols is essential to achieve these goals.

The complexity of aerosol therapy in ventilator-dependent patients is due to the interaction of a host of factors that determine drug deposition in the lung. During the past 2 decades, impressive gains in knowledge about the interplay of these factors, for example, humidity, duty cycle, and device configuration and placement in the circuit, have contributed immensely to improved methods for aerosol delivery. ${ }^{(8)}$ Newer designs of nebulizers that employ a vibrating plate with multiple apertures to generate aerosol ${ }^{(9)}$ and hydrofluoroalkane (HFA)-propelled pMDIs ${ }^{(10,11)}$ also significantly influence delivery of aerosols during mechanical ventilation. The purpose of this article is to review the scientific principles underlying the use of inhaled therapies in adult mechanically ventilated patients, with an emphasis on recently published literature.

\section{Factors Influencing Aerosol Delivery During Mechanical Ventilation: Lessons From the Bench}

\section{pMDIs}

Over the past 25 years, the pMDI has been accepted as a cost effective, convenient, reliable, and safe aerosol generator for use with mechanically ventilated patients. ${ }^{(12)}$ As pMDIs were never designed or intended for delivery of inhaled medications to mechanically ventilated patients, their adaptation for efficient aerosol delivery in this setting involved substantial innovation and experimentation. For pMDIs to be employed in ventilator-supported patients, third-party actuator devices that could be connected in closed, pressurized circuits were required. These devices range from simple adapters with a port and single nozzle to more complex spacer chambers. ${ }^{(13-16)}$ The performance of these devices varies between adapter designs, and within the same adapter type between pMDI formulations, including both the drug and the propellants used. In vitro studies have shown that aerosol drug delivery to the lower respiratory tract ranges from 0.3 to $97.5 \%$ with pMDIs. ${ }^{(2,5,6,17-21)}$ This level of variability in drug delivery can spell the difference between effective and unsuccessful therapy.

Most of the data regarding the relative attributes of these devices is based on reported in vitro testing by individual investigators. Multiple factors influencing the efficiency of aerosol delivery with pMDIs are discussed below:

1. Timing of actuation: The timing of pMDI actuation in relation to the ventilator airflow has a marked influence on delivered dose of medication. According to Diot et al., ${ }^{(20)}$ failure to synchronize actuations with inspiration reduced inhaled mass by $35 \%$. Likewise, Alzahrani and colleagues ${ }^{(22)}$ reported that actuations of a pMDI repeated every $15 \mathrm{~s}$ independent of the breathing pattern resulted in a lower inhaled mass $(3.7 \pm 1.3 \%$ of the emitted dose) compared to actuations synchronized with the start of inspiration, and with more than a 15-s interval between successive actuations (14.47 $\pm 2.5 \%)$. By using a model of noninvasive ventilation, Branconnier and Hess ${ }^{(23)}$ reported that actuation at the onset of inspiration resulted in at least $40 \%$ higher inhaled dose than actuation during expiration. Actuation of a pMDI must be synchronized with the precise onset of inspiration to maximize aerosol drug delivery.

2. Priming and shaking the canister: All manufacturers recommend shaking and priming the pMDI with several actuations to the atmosphere prior to first use, and after specified periods of time between uses. ${ }^{(24)}$ With the transition from chlorofluorocarbon (CFC) to HFA propellants, recommended periods between priming have been extended up to several days. However, the failure to shake a pMDI canister that has been standing overnight may decrease total emitted and respirable dose by as much 25 and $35 \%$, respectively, because the drugs in pMDI formulations tend to separate from their propellants during this interval. ${ }^{(25)}$ Therefore, it is good practice to prime a pMDI before first use and if it has not been actuated for more than $24 \mathrm{~h}$. pMDIs should be shaken before the first actuation of each dose (series of actuations) administered. However, once shaken, up to eight actuations from a pMDI can be sequentially administered within a short time period without a reduction in emitted dose. ${ }^{(5)}$ Similarly, during mechanical ventilation pMDI actuation at 15-s intervals resulted in emitted doses that were comparable to those obtained by actuation after the 1- min interval recommended on the device label. ${ }^{(5)}$

3. Actuator designs: Several actuators with different designs and sizes are available on the market for aerosol drug delivery in mechanically ventilated patients. Rau et al. ${ }^{(18)}$ tested the efficiency of three different setups: an elbow adapter at the endotracheal tube (ETT); an in-line spacer chamber (Aerovent, Monaghan Medical, Plattsburgh, NY) placed in the inspiratory limb just before the $\mathrm{Y}$ adapter; and an in-line chamber placed between the $\mathrm{Y}$ and endotracheal tube. A total of 10 actuations were administered at 30-s intervals in a dry circuit. The pMDI with elbow adapter delivered the least $(7.3 \%)$, whereas the chamber delivered $32.1 \%$ when placed in the inspiratory limb, and $29 \%$ deposition when placed at the ETT.

Subsequent studies confirmed that the use of a chamber shaped spacer with the pMDI results in fourto sixfold greater aerosol drug delivery when compared with either an elbow adapter or a unidirectional in-line spacer. ${ }^{(18,26,27)}$ In contrast, the efficiency of a bidirectional in-line spacer was higher than the efficiency of a unidirectional in-line spacer and it achieved comparable efficiency with chamber spacers. ${ }^{(28)}$

4. Placement of the PMDI in the ventilator circuit: Placing the spacer chamber in the inspiratory limb of the ventilator circuit, $15 \mathrm{~cm}$ from the ETT increases aerosol deposition with improved potential for clinical response. ${ }^{(23,29)}$ Ari and colleagues, ${ }^{(17)}$ using a heated/humidified in vitro model of adult ventilation quantified the percent of emitted dose delivered distal to an endotracheal tube from an albuterol HFA-pMDI with chamber adapter, in each of three positions: between ETT and Y-piece 
(7.6 $\pm 1.3 \%)$, in the inspiratory limb $15 \mathrm{~cm}$ from Y-piece $(17.0 \pm 1.0 \%)$, and $15 \mathrm{~cm}$ from the ventilator before the inlet of the humidifier $(2.5 \pm 0.8 \%)$. The deposition efficiency achieved with placement of the pMDI and chamber adapter $15 \mathrm{~cm}$ from the $\mathrm{Y}$ piece $(17 \%$ of the emitted dose) was similar to that achieved using ultrasonic and vibrating mesh nebulizers in the same position.

5. Heat and humidity: Bench models of mechanical ventilation clearly established that aerosol drug delivery is reduced by up to $40 \%$ in heated/humidified ventilator circuits compared to nonhumidified unheated circuits. ${ }^{(5,6,20,30-32)}$ Although higher deposition with delivery of cold dry gas might seem attractive as a means to deliver more drug to the lung, the increased efficiency of aerosol delivery must be weighed against the potential deleterious effects of prolonged ventilation with cold dry gases. ${ }^{(32)}$ Active heated humidifiers are commonly used during mechanical ventilation of infants and small children, and a substantial proportion of adults. The heat and humidity of an inhaled gas to body temperature pressure saturated (BTPS) conditions promotes mucociliary clearance, prevents drying of the airway mucosa, and reduces bronchospastic responses to breathing cold dry air. The reduction in aerosol delivery with heated humidity in the ventilator circuit has been associated with changes in aerosol particle size during mechanical ventilation. ${ }^{(5,6,20,30-32)}$ However, Lange and Finlay ${ }^{(33)}$ demonstrated that the decrease in inhaled drug mass was directly related to the mole fraction of water vapor in the inspired air, rather than to the relative humidity or the temperature of the inhaled gas. These investigators demonstrated that hygroscopic growth was not responsible for the excessive drug losses in the spacer and ETT, and they hypothesized that an interaction between the water molecules in the air and the surfactant present in the propellant/drug suspension may have caused a reduction in the evaporation rate of propellant. ${ }^{(33)}$ In addition, they also reported that drug delivery in a ventilator circuit with a correctly dimensioned spacer could be even more efficient than under ambient conditions in spontaneously breathing patients. ${ }^{(33)}$

Despite the unwanted effects of humidity on drug delivery, removing the humidifier is not recommended for routine aerosol therapy as it requires breaking the circuit and waiting several minutes for the circuit to dry. ${ }^{(34)}$ Moreover, the effects of turning off the heated humidifier on aerosol delivery are difficult to predict. For example, efficiency of albuterol delivery from a pMDI with spacer chamber during mechanical ventilation with a heated wire circuit was not reduced for more than $1 \mathrm{~h}$ after turning on the heated humidifier. ${ }^{(35)}$ Aerosol delivery was decreased when substantial condensation was noted in the spacer and tubing, with reductions to levels previously reported with humidified ventilator circuits. After $3 \mathrm{~h}$ of humidifier operation, turning off the humidifier for up to $30 \mathrm{~min}$ prior to administration of aerosol via pMDI did not improve drug delivery. ${ }^{(35)}$ As suggested by the authors, ${ }^{(35)}$ the presence of water condensate probably achieved a high enough absolute humidity in the circuit and chamber that continued to reduce delivery efficiency of the inhaled aerosol for some time interval after turning off the humidifier.

For inexpensive drugs, such as salbutamol or ipratropium bromide, increasing the administered dose of drug may be safer than turning off the humidifier. For more expensive drugs, such as antibiotics, the potential efficiency advantage of a dry ventilator circuit may be cost-effective; however, this has yet to be demonstrated in vivo. If a dry ventilator circuit needs to be used for aerosol delivery, a heat moisture exchanger (HME) should be employed, and the medication administered within a short period (less than $10 \mathrm{~min}$ ) to minimize the dehydrating effects on the airway mucosa. ${ }^{(36)}$

Heat and moisture exchangers (HMEs) capture the heat and moisture in the exhaled air and transfer part of the heat and humidity to the next inspired breath, providing about $70 \%$ absolute humidity at $30^{\circ} \mathrm{C}$. The filter in the HME, presents a formidable barrier to aerosol delivery, and it must never be placed between the aerosol-generating device and the patient during aerosol administration. In addition, during nebulization for extended periods the nebulizer output has the potential to overload the HME filter with both drug and liquid, and increase the work of breathing through the device.

6. Density of inhaled gas: High inspiratory flow during mechanical ventilation produces transitional and turbulent flows in the narrow airway passages that causes aerosol to impact on the ventilator circuit and in the artificial airway. ${ }^{(37)}$ Inhaling a helium-oxygen mixture allows laminar flows to persist in the airways, and may improve aerosol deposition by decreasing impaction losses caused by airflow turbulence. ${ }^{(38)}$ In a bench model of mechanical ventilation, Goode and colleagues ${ }^{(39)}$ reported that a $80 / 20$ helium/oxygen (Heliox) mixture increased aerosol deposition from pMDIs and nebulizers up to $50 \%$ when compared to using oxygen alone. Aerosol delivery efficiency and gas density in the ventilator circuit are inversely related. The lowest gas density ( $80 / 20$ helium/oxygen) provides the highest bronchodilator delivery but it also reduces aerosol generation with a jet nebulizer. ${ }^{(39)}$

Because of its lower density, heliox is not as effective in aerosolizing liquid medications via jet nebulization, and it should not be used to power the nebulizer. ${ }^{(39,40)}$ When a helium/oxygen mixture is employed, flow to the nebulizer must be increased by twofold or more than flows of air or oxygen in order to achieve a comparable aerosol output. ${ }^{(39,41)}$ A preferred strategy in maximizing aerosol deposition with a nebulizer is to power it with 6 to $8 \mathrm{~L} / \mathrm{min}$ of oxygen and entrain the aerosol into a ventilator circuit that contains heliox. ${ }^{(39,40)}$ Tassaux et al. ${ }^{(42)}$ showed that aerosol deposition to the lower airways is increased by $50 \%$ with that method compared to using oxygen alone in the ventilator circuit. Heliox may adversely affect the function of some ventilators, so the ventilator must be tested with heliox to detect any malfunction before use in patients. ${ }^{(42)}$

As a practical consideration, the available drug options available in pMDIs are limited. Relative cost effectiveness of the pMDI has shifted as the costs of HFA-pMDIs have risen, sometimes dramatically, over their CFC-propelled 
predecessors. For example, each dose of four puffs of albuterol from a HFA-pMDI (\$140 for 200 puffs) would cost $\$ 2.80$, compared to a unit dose of the liquid formulation that costs less than $\$ 1$.

In summary, pMDIs offer a safe and effective method for administration of medications to the lungs of patients requiring mechanical ventilator support. If the prescribed drugs are available in this dosage form, and a standard dose provides the desired clinical response, then the pMDI is an excellent option. Careful attention to the details of administration, such as the timing of actuation, actuators used, and placement of the device in the ventilator circuit, are required to optimize therapy.

\section{Nebulizers}

Three principal designs of nebulizers, namely jet nebulizers, ultrasonic nebulizers and mesh nebulizers, are employed to deliver liquid formulations of medications such as bronchodilators, antibiotics, corticosteroids, surfactant, mucolytic agents, anticoagulants, and prostanoids to mechanically ventilated patients (Table 1 ).

Jet Nebulizers. For the past several decades, jet nebulizers have been commonly employed for aerosol delivery during mechanical ventilation because they are readily available in most hospitals, easy to use, and relatively inexpensive compared with vibrating mesh and ultrasonic nebulizers. However, entrainment of an additional 2-10 L/min of gas into the ventilator circuit during nebulizer operation could influence tidal volumes and pressures delivered to the patient. Also, jet nebulizers may inactivate or denature the drug due to shear forces generated during the process of nebulization. ${ }^{(43-45)}$ The medication reservoir also serves as the nebulization chamber. As larger particles are produced, they return to the medication reservoir and the medication is renebulized, resulting in evaporative effects associated with increasing concentration of medication over time. In addition, residual drug volumes remaining in the reservoir at the

Table 1. Inhaled Medications Employed During Mechanical Ventilation

Bronchodilator
Beta-agonist (albuterol, terbutaline, metaproteronol,
fenoterol)
Anticholinergic (ipratropium bromide)
Combination beta-agonist and anticholinergic
(albuterol sulfate+ipratropium bromide)
Combination long-acting beta-agonist and inhaled
$\quad$ corticosteroid (salmeterol + fluticasone;
$\quad$ formoterol + budesonide)
Prostaglandins
Mucoactive agents
Dornase alpha
Surfactant
Antibiotics
Antibacterial
Antiviral
Antifungal
Corticosteroids (beclomethasone; budesonide, fluticasone)
Anticoagulants (Heparin)
Miscellaneous

end of nebulization range from $0.8-1.4 \mathrm{~mL}$ with various jet nebulizers. Such operational inefficiencies of jet nebulizers make them less than ideal for many patients receiving mechanical ventilation.

Ultrasonic nebulizers. Although several brands of ultrasonic nebulizers are available, they are not commonly employed during mechanical ventilation due to their bulkiness, high cost, production of aerosols with larger particle size than jet nebulizers, relative inefficiency to aerosolize viscous solutions or suspensions, and degradation of heat-sensitive materials. ${ }^{(46-48)}$ Typical residual volumes of drug remaining at end of nebulization in various ultrasonic nebulizer brands range from $0.5-1.0 \mathrm{~mL}$.

Vibrating mesh nebulizers. The vibrating mesh nebulizers are associated with higher efficiency than jet or ultrasonic nebulizers, due in part to the lower residual volume (ranging from $0.1-0.5 \mathrm{~mL}$ ). ${ }^{(13)}$ Unlike other nebulizers (jet or ultrasonic), the medication reservoir in vibrating mesh nebulizers is separated from the ventilator circuit and lies above the mesh and the ventilator circuit. Because of this orientation, the risk of contaminated condensate entering the medication reservoir is reduced. Because vibrating mesh nebulizers generally produce aerosols with a higher respirable fraction, the nominal dose of drugs to be administered for clinical effects could be reduced compared to jet nebulizers. ${ }^{(9,43)}$ Other advantages of the vibrating mesh nebulizers are that they can be battery operated, and thus are more portable and less noisy than jet nebulizers. Because vibrating mesh nebulizers neither cool nor heat the solution, there is minimal risk of denaturation and they could be safely employed to aerosolize complex microstructures and large molecules. ${ }^{(49)}$ For instance, Perera et al. ${ }^{(50)}$ showed that repeated administration of inhaled insulin results in comparable dosing reproducibility and shorter time to maximal metabolic effect compared with subcutaneously administered insulin. They found that the delivery of inhaled insulin through a mesh nebulizer is well tolerated by patients and concluded that the delivery system for delivering inhaled insulin is clinically applicable.

Many factors influence nebulizer efficiency during mechanical ventilation, including the type of nebulizer, residual volume, mode of nebulization, position of nebulizer in the ventilator circuit, gas flow, and bias flow. ${ }^{(32)}$ Such factors influence the emitted dose and make it harder to provide objective comparisons of clinical outcomes. Although aerosol delivery during mechanical ventilation has been studied extensively in vitro, testing of nebulizers has been much less rigorous in vivo.

1. Type of nebulizer: Both the type of nebulizer and different batches of the same nebulizer brand show variability in aerosol output. ${ }^{(17,51-53)}$ Jet nebulizers are less efficient than ultrasonic and vibrating mesh nebulizers, ${ }^{(9,13,17,53-55)}$ because the latter provide a higher rate of nebulization in a shorter period of time. $(9,17,34,53,56)$ Alvine et al. ${ }^{(51)}$ evaluated the nebulization rate and particle size of eight disposable jet nebulizers and found considerable variability of nebulization rate within specific models. ${ }^{(51)}$ Loffert et al. ${ }^{(57)}$ tested 17 commercially available jet nebulizers by filling them with $2 \mathrm{~mL}$ 
of saline solution and $0.5 \mathrm{~mL}$ of albuterol. They found that the output characteristics of commercial nebulizers vary greatly in terms of nebulization time and the total amount of drug delivered to the lungs. ${ }^{(57)}$ Therefore, the efficiency of a nebulizer must be characterized before using it for drug delivery to mechanically ventilated patients.

2. Residual (dead) volume: Residual volume, that is, the amount of medication remaining in the nebulizer at the end of a treatment, can range from 0.1 to $2.4 \mathrm{~mL}$ depending on the type of nebulizer. Jet nebulizers have a higher residual volume, nebulize less of a proportion of the drug, and do not function well with fill volumes below $2 \mathrm{~mL}$. $^{(13)}$ Therefore with jet nebulizers, it is recommended to use a fill volume of $4-5 \mathrm{~mL}$ unless the nebulizer is specifically designed for a smaller fill volume. ${ }^{(52)}$ Vibrating mesh nebulizers have smaller residual volumes than jet and ultrasonic nebulizers. ${ }^{(13,45,58)}$ Compared to jet nebulizers, the higher costs of ultrasonic and mesh nebulizers has limited their utilization in ventilated patients.

3. Nebulizer position in the ventilator circuit: Placement of a jet nebulizer farther away from the endotracheal tube improves aerosol delivery ${ }^{(17,30,53,59-61)}$ because the ventilator tubing acts as a spacer in which the aerosol accumulates between breaths. The continuous output of gas from the jet nebulizer charges the inspiratory limb of the circuit between inspirations, increasing the proportion of drug output delivered with each ventilator breath. This explanation was confirmed by Ari et al., ${ }^{(17)}$ who reported that during conventional ventilation with no bias flow, placement of a pMDI, ultrasonic nebulizer, or vibrating mesh nebulizer proximal to the ventilator reduced delivery compared to standard placement proximal to the patient. Although it may seem counterintuitive to place an aerosol generator before the inlet of the humidifier, these investigators noted that in the presence of bias flow, delivery efficiency of the vibrating mesh nebulizer was greater when it was placed in proximity with the ventilator (Fig. 1). The clinical relevance of this observation is unclear, because in a clinical study Moraine et al. ${ }^{(62)}$ reported that the placement of a vibrating mesh nebulizer in close proximity to the ventilator, that is, before the humidifier, did not affect the urinary excretion of ipratropium bromide compared to placement in the inspiratory limb near the circuit $\mathrm{Y}$. 4. Bias flow (trigger flow): Ari et al. ${ }^{(53)}$ studied the influence of bias flow with a jet and vibrating mesh nebulizer on albuterol sulfate delivery in a model of adult mechanical ventilation. They reported that increasing bias flows through the ventilator circuit decreased the amount of aerosol deposited. During continuous nebulization,

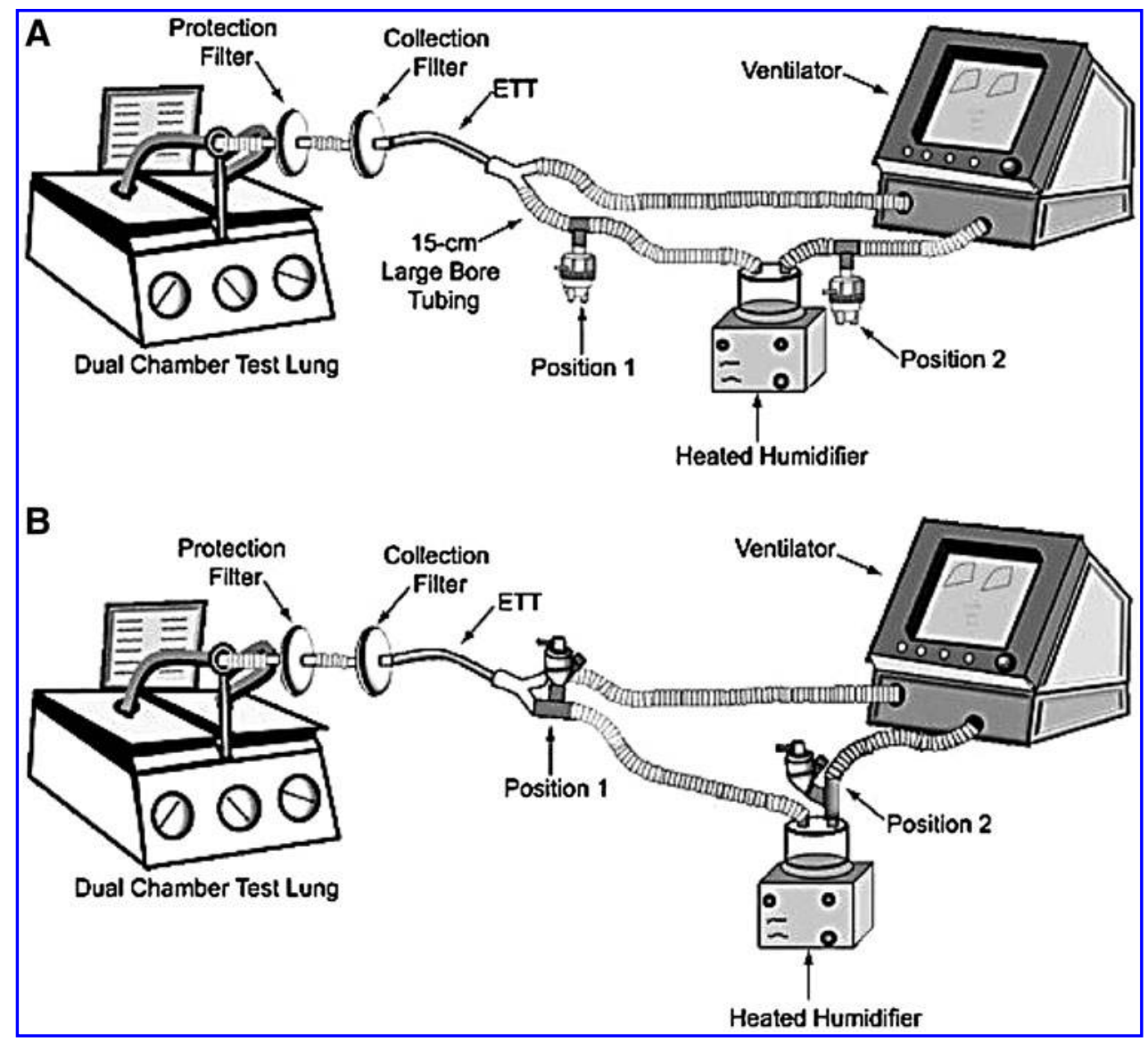

FIG. 1. Key components of an in vitro setup to quantify delivery of aerosol drug distal to the endotracheal tube during mechanical ventilation, with placement of a jet nebulizer (A) and vibrating mesh nebulizer (B) in the inspiratory limb proximal to the patient (position 1) and proximal to the ventilator (position 2). (Reproduced with permission, from Ari et al. ${ }^{(53)}$ ) 
they recommended that aerosol delivery could be enhanced by reducing bias flow to $\leq 2 \mathrm{~L} / \mathrm{min}$. ${ }^{(53)}$

5. Mode of nebulization. Pressurized gas from a 50 psi wall outlet or gas cylinder is commonly employed to operate nebulizers continuously. Alternatively, nebulizers may be operated by driving pressure and gas flow from the ventilator, and this intermittent operation allows the ventilator to maintain a constant tidal volume and minute ventilation by compensating for the nebulizer flow. Intermittent nebulizer operation synchronized with inspiratory airflow from the ventilator minimizes aerosol losses during exhalation, and has a 35 to $400 \%$ higher efficiency for drug delivery than continuous nebulization. ${ }^{(60,63)}$ However, the lower driving gas pressure provided by some ventilators may influence the efficiency and quality of nebulizer output. The efficiency of breath actuation may also be influenced by the time gap between initiation of powering the nebulizer and aerosol generation. This time gap may be up to $80 \mathrm{~ms}$ with jet nebulizers and $>150 \mathrm{~ms}$ with ultrasonic nebulizers. Built-in nebulizer functionality in some newer generation ventilators takes into account changes with nebulizer operation, and facilitates more reproducible and consistent dosing. ${ }^{(36,64,65)}$

6. Gas flow. Each model of jet nebulizers is designed to work best at a specific flow, ranging from 2-10 L/min, which should be listed on the device label. Operating any jet nebulizer at a lower flow or pressure increases aerosol particle size, and thereby reduces pulmonary drug delivery. Moreover, reducing the gas flow produces a proportionate increase in nebulization time. In contrast to jet nebulizers, ultrasonic and vibrating mesh nebulizers are operated by electricity and they are not influenced by gas flow.

In summary, nebulizer operation during mechanical ventilation could have widely variable efficiency for aerosol delivery unless careful attention is given to a number of factors that influence nebulizer performance.

\section{Soft-mist inhaler}

A new adapter has been designed for in-line use of the Respimat soft mist inhaler (Boehringer-Ingelheim, Germany). The in vitro dose delivery of tiotropium, and ipratropium bromide and albuterol in combination, was compared with pMDI delivery using different valved holding chambers and spacers during simulated mechanical ventilation. The Respimat with the prototype in-line adapter provided better fine particle dose delivery than other accessory device combinations. ${ }^{(66)}$

\section{Assessment of Aerosol Deposition in Mechanically Ventilated Patients}

Several investigators have used radionuclides and measured plasma or urinary drug levels to determine pulmonary deposition of aerosols in ventilated patients.

\section{Radionuclide studies}

In ventilated patients, the pulmonary deposition of nebulized radiolabeled aerosol has varied by more than 25 -fold
( $\sim 1$ to $\sim 30 \%$ of the nominal dose)..$^{(2,21,59,67)}$ Several factors, including type of radiolabel used, nebulizer brand, treatment time, circuit humidity, and methods used to calculate the amount of aerosol deposition, ${ }^{(30,63,67)}$ contribute to the reported variation. With a pMDI and spacer chamber, about $6 \%$ of the dose was deposited in the lower respiratory tract, ${ }^{(21,27)}$ and this value was significantly lower than previously reported values (10-20\%) with a pMDI and spacer in nonintubated ambulatory patients. ${ }^{(68,69)}$

\section{Pharmacokinetic studies}

Estimation of plasma levels of drugs administered by a $\mathrm{pMDI} /$ nebulizer reflects lower respiratory tract deposition in ventilated patients because the endotracheal tube prevents oropharyngeal deposition and subsequent enteral absorption during inspiration. There is the potential for exhaled drug to bypass the ETT cuff and deposit in the oropharynx, but this amount is generally minimal and should not make a significant contribution to the plasma levels. After administration of albuterol with a pMDI and spacer, the area under the concentration-time curve was only marginally lower in ventilated patients than in healthy controls. ${ }^{(70)}$ Moreover, measurement of urinary albuterol excretion in 30 ventilated patients with normal renal function showed that albuterol recovery was highest (38\% of the nominal dose) after administration with a pMDI and chamber spacer, intermediate with a nebulizer $(16 \%)$, and lowest $(9 \%)$ with a pMDI and right angle port connected to the endotracheal tube. ${ }^{(71)}$ With an optimal technique of administration, pulmonary drug deposition in ventilated patients is comparable to that achieved in healthy controls. Measurement of urinary drug excretion has also been employed to compare the efficiency of drug delivery during mechanical ventilation. Moraine et al. ${ }^{(62)}$ measured urinary ipratropium levels after ultrasonic nebulization in ventilated patients, and found no differences in urinary ipratropium levels with the nebulizer placed close to the circuit $\mathrm{Y}$ or when it was placed before the heated humidifier. In ventilated patients, pharmacokinetic studies could be a useful adjunct to in vitro studies for comparing device efficiency, and to establish optimal techniques of administration with specific devices.

\section{In vitro/In vivo correlation}

In vitro tests play an important role in elucidating the contribution of each of a complex array of factors influencing drug delivery. ${ }^{(5-8)}$ The wide discrepancy between in vitro and in vivo estimates of aerosol delivery has been reconciled by comparing data from bench models with in vivo scintigraphic studies. ${ }^{(6)}$

In vitro models commonly use an absolute filter to collect drug distal to the artificial airway. This is likely to overestimate in vivo deposition, because the filter deposition measures inhaled mass, and some of this inhaled aerosol does not deposit in the lung and is exhaled. Thus, the filter deposition does not account for the proportion of drug that is exhaled by the patient. ${ }^{(6,72)}$ When the difference between drug exhaled in vitro and in vivo is subtracted from the in vitro drug deposited distal to the ETT, the calculated dose is comparable to pulmonary deposition of radiolabeled aerosol in mechanically ventilated patients after adjusting for tissue absorption of radioactivity. ${ }^{(6,27)}$ 


\section{Bronchodilator Therapy}

Bronchodilators are among the most commonly used drugs in the intensive care unit (ICU), ${ }^{(73)}$ but many other inhaled medications are also employed during mechanical ventilation (Table 1). Table 2 shows the indications for using bronchodilator therapy in ventilator-supported patients. The goals of bronchodilator therapy are to reverse bronchoconstriction, decrease the work of breathing, and/or relieve dyspnea. Administration of either aerosolized $\beta$-adrener$\operatorname{gic}^{(26,29,74-93)}$ or anticholinergic drugs ${ }^{(77,79,83,86)}$ produces significant bronchodilator responses in ventilated patients. The combination of fenoterol and ipratropium bromide was found more effective than ipratropium alone in ventilated patients with COPD. ${ }^{(94)}$

Combinations of inhaled corticosteroids (ICS) plus longacting $\beta$-agonist (LABA) (Advair, GSK, Research Triangle Park, NC; Symbicort Astra Zeneca, Wilmington, DE) are among the most effective and widely used treatments currently available for treatment of asthma. A combination of formoterol and budesonide used as a reliever as well as maintenance therapy may be employed for treatment of mild to moderate acute asthma exacerbations that could be managed at home. This management strategy significantly reduces the frequency of more severe exacerbations. ${ }^{(95)}$ Currently, there is limited experience with bronchodilator and ICS combination therapy for treatment of acute exacerbations of chronic obstructive pulmonary disease (COPD), especially in ventilated patients.

In patients receiving long-term ventilation for severe COPD, Nava and colleagues ${ }^{(96)}$ observed a small but statistically significant reduction in airway resistance with inhaled fluticasone. The optimal methods of administering ICS and the appropriate doses in ventilated patients have not been determined, but, based on the experience with asthma and COPD patients in the Emergency Department, they are likely to be higher than those used for maintenance therapy for these disorders. ${ }^{(97-100)}$ Significant costs could accrue from inhaled therapy with a ICS and LABA combination, especially if higher doses are needed. Furthermore, many ventilated patients receive systemic corticosteroids for acute exacerbations of asthma and COPD, and it is unclear if patients derive additional benefits from ICS in the presence of high-dose therapy with oral or parenteral corticosteroids. Finally, regular use of ICS in ambulatory patients with COPD is associated with a higher risk of pneumonia. ${ }^{(101)}$ Because ventilated patients are already vulnerable to developing pneumonia for a variety of reasons, the potential to add another risk factor by administering ICS requires serious

TABle 2. INDICATIONS FOR BRONCHODILATOR THERAPY in Patients Receiving Mechanical Ventilation

1. Severe asthma

2. COPD

3. Acute bronchospasm or wheezing

4. Elevated airway resistance

5. Dynamic hyperinflation/intrinsic PEEP

6. Difficulty in weaning

7. Chronic ventilator-dependence

COPD, chronic obstructive pulmonary disease; PEEP, positive end-expiratory pressure. consideration. In summary, ICS may have a limited role in ventilated patients, but further investigations are needed to determine the appropriate dosing regimen and risk-benefit of using ICS or ICS and LABA in this group of patients.

\section{Bronchodilator efficacy}

Most mechanically ventilated patients with COPD demonstrate an improvement in respiratory mechanics following bronchodilator administration with a pMDI or a nebulizer (Table 3). ${ }^{(26,88)}$ Application of external positive endexpiratory pressure (PEEP) at a level that counterbalanced intrinsic PEEP enhanced the bronchodilator effect of albuterol in mechanically ventilated patients with COPD. ${ }^{(91)}$ In contrast, Guerin and colleagues ${ }^{(102)}$ reported that after administration of nebulized fenoterol respiratory mechanics improved when PEEP was set a zero. Increasing the set PEEP to $85 \%$ of the intrinsic PEEP level did not enhance the bronchodilator response. The use of a spacer with a pMDI also improves the efficacy of bronchodilator therapy in ventilator-supported patients. The best results are obtained when the pMDI actuation is synchronized with the onset of inspiration. $^{(3,8)}$ With careful attention to the technique of administration, a bronchodilator response can be expected in most mechanically ventilated patients with asthma or COPD.

In mechanically ventilated patients, significant bronchodilator effects occur after administration of $2.5 \mathrm{mg}$ of albuterol with a standard nebulizer, ${ }^{(82,88)}$ or four puffs $(400 \mu \mathrm{g})$ with a pMDI (Fig. 2) (Table 3 ). ${ }^{(103)}$ Minimal therapeutic advantage was gained by administering higher doses, whereas the potential for side effects was increased. ${ }^{(82,103)}$ In certain clinical settings, higher doses of bronchodilators may be needed in patients with severe airway obstruction or if the technique of administration is not optimal. With a carefully executed technique of administration (Tables 4 and 5), most stable mechanically ventilated patients with COPD achieve near maximal bronchodilation following administration of four puffs of albuterol with a pMDI or $2.5 \mathrm{mg}$ with a nebulizer (Fig. 2). ${ }^{(40)}$

The duration of bronchodilator response in stable mechanically ventilated patients with COPD appears to be shorter than that in ambulatory patients (2-3h vs. $4-6 \mathrm{~h}$, respectively) and subject to considerable interpatient variability. ${ }^{(88,90)}$ Thus, ventilated patients should receive scheduled administration of short-acting $\beta$-agonist bronchodilator (albuterol) every 3 to $4 \mathrm{~h}$.

In addition to patients with confirmed expiratory airflow obstruction due to asthma or COPD, expiratory flow was also shown to improve after bronchodilator administration in a heterogeneous group of ventilated patients. ${ }^{(76)} \mathrm{Neb}-$ ulized metaproterenol reduced elevated levels of airway resistance in patients with acute respiratory distress syndrome (ARDS). ${ }^{(104,105)} \beta$-Agonists could also enhance clearance of fluid from the alveoli and accelerate the resolution of alveolar edema in patients with acute lung injury or acute respiratory distress syndrome (ARDS). However, a recently concluded multicenter trial by the ARDS Network found that administration of nebulized albuterol ( $5 \mathrm{mg}$ every $4 \mathrm{~h}$ for up to 10 days) did not improve ventilator-free days, or mortality at 60 days or 90 days after enrolment. ${ }^{(106)}$ Although bronchodilators are currently administered to a wide spectrum of patients receiving mechanical ventilation, with associated 
Table 3. Investigations of Bronchodilator Therapy and Airway Response in Mechanically Ventilated Patients

\begin{tabular}{|c|c|c|}
\hline $\begin{array}{l}\text { Author, year } \\
\text { (reference \#) }\end{array}$ & Drug (dose, mg) & Aerosol device \\
\hline Gay, $1987^{(76)}$ & $\begin{array}{l}\text { Metaproterenol } \\
\quad(1.8 \mathrm{mg})\end{array}$ & $\begin{array}{l}\text { Small-volume aerosol } \\
\text { generator }\end{array}$ \\
\hline Wegener, $1987^{(77}$ ) & $\begin{array}{l}\text { Ipratropium } \\
(0.2 \mathrm{mg})\end{array}$ & pMDI and adapter \\
\hline Fuller, $1990^{(21)}$ & $\begin{array}{l}\text { Fenoterol }(0.8 \mathrm{mg}) \\
\text { Fenoterol } \\
(1.75 \mathrm{mg})\end{array}$ & $\begin{array}{l}\text { pMDI-spacer } \\
\text { Nebulizer }\end{array}$ \\
\hline Fernandez, $1990^{(79)}$ & $\begin{array}{l}\text { Albuterol }(0.2 \mathrm{mg}) \\
\text { or Ipratropium } \\
(0.04 \mathrm{mg})\end{array}$ & $\begin{array}{l}\text { pMDI and short } \\
\text { catheter }\end{array}$ \\
\hline Bernasconi, $1990^{(78)}$ & $\begin{array}{l}\text { Fenoterol }(0.4,0.8, \\
1.2 \mathrm{mg})\end{array}$ & $\begin{array}{l}\text { Small-volume aerosol } \\
\text { generator and jet } \\
\text { nebulizer }\end{array}$ \\
\hline Mancebo, $1991^{(81)}$ & Albuterol (1.0 mg) & pMDI-spacer \\
\hline Gay, $1991^{(80)}$ & $\begin{array}{l}\text { Albuterol }(0.3 \mathrm{mg}) \\
\text { Albuterol } \\
(2.5 \mathrm{mg})\end{array}$ & $\begin{array}{l}\text { pMDI and adapter } \\
\text { Nebulizer }\end{array}$ \\
\hline Manthous , $1993^{(82)}$ & $\begin{array}{l}\text { Albuterol (up to } \\
10 \mathrm{mg}) \\
\text { Albuterol (2.5, } \\
5.7 .5 \mathrm{mg})\end{array}$ & $\begin{array}{l}\text { pMDI and elbow } \\
\text { adapter } \\
\text { Nebulizer }\end{array}$ \\
\hline Yang, $1994^{(83)}$ & $\begin{array}{l}\text { Ipratropium } \\
(0.5 \mathrm{mg})\end{array}$ & Nebulizer \\
\hline Fernandez, $1994^{(94)}$ & $\begin{array}{l}\text { Fenoterol } \\
\quad(0.1 \mathrm{mg})+ \\
\text { Ipratropium } \\
(0.04 \mathrm{mg})\end{array}$ & $\begin{array}{l}\text { pMDI and short } \\
\text { catheter }\end{array}$ \\
\hline Dhand, $1995^{(26)}$ & Albuterol $(1.0 \mathrm{mg})$ & pMDI-spacer \\
\hline Manthous, $1993^{(82)}$ & $\begin{array}{l}\text { Albuterol }(0.5,1.5, \\
3.0 \mathrm{mg} \\
\text { cumulative } \\
\text { dose) }\end{array}$ & pMDI-spacer \\
\hline Dhand, $1996^{(29)}$ & $\begin{array}{l}\text { Albuterol }(0.4,1.2, \\
2.8 \mathrm{mg} \\
\text { cumulative } \\
\text { dose) }\end{array}$ & pMDI-spacer \\
\hline Mouloudi, $1998^{(84)}$ & $\begin{array}{l}\text { Albuterol }(0.6 \mathrm{mg}) \\
\text { with or without } \\
\text { end-inspiratory } \\
\text { pause }\end{array}$ & pMDI-spacer \\
\hline Waugh, $1998^{(85)}$ & $\begin{array}{l}\text { Albuterol (0.4, } \\
\quad 0.8 \mathrm{mg})\end{array}$ & $\begin{array}{l}\text { pMDI and chamber } \\
\text { spacers }\end{array}$ \\
\hline Mouloudi, $1999^{(87)}$ & Albuterol (0.6 mg) & pMDI-spacer \\
\hline Guerin, $1999^{(86)}$ & $\begin{array}{l}\text { Fenoterol } \\
\quad(0.2 \mathrm{mg})+ \\
\text { Ipratropium } \\
(0.4 \mathrm{mg}) \\
\text { Fenoterol } \\
(1.25 \mathrm{mg})+ \\
\text { Ipratropium } \\
(0.5 \mathrm{mg})\end{array}$ & $\begin{array}{l}\text { pMDI-spacer } \\
\text { Nebulizer }\end{array}$ \\
\hline Duarte, $2000^{(88)}$ & $\begin{array}{l}\text { Albuterol }(0.4, \\
1.0 \mathrm{mg}) \\
\text { Albuterol } \\
2.5 \mathrm{mg}\end{array}$ & $\begin{array}{l}\text { pMDI-spacer } \\
\text { Nebulizer }\end{array}$ \\
\hline
\end{tabular}

Response

Increase in expiratory flow at recoil pressure of $6 \mathrm{~cm}$ $\mathrm{H}_{2} \mathrm{O}$, and reduction in peak pressure and intrinsic PEEP

Decrease in inspiratory airway resistance and significant increase in $\mathrm{paO}_{2}$

Decrease in peak airway pressure not significant with either device

Significant decrease in peak airway pressure and intrinsic PEEP

Significant decrease in airway resistance, endexpiratory lung volume and intrinsic PEEP

Significant decrease in airway resistance

Similar reductions in expiratory airflow resistance with each delivery device

No change in airway resistance with pMDI, significant reduction with nebulizer

Significant reduction in peak airway pressure, mean airway pressure and mean airway resistance

Significant decrease in airway resistance with combination

Significant reduction of airway resistance for up to $60 \mathrm{~min}$

Significant reduction in airway resistance with 1.5 and $3.0 \mathrm{mg}$ albuterol

Significant reduction in airway resistance with $0.4,1.2$ and $2.8 \mathrm{mg}$ of albuterol

Significant reduction in airway resistance. No effect of end-inspiratory pause

Reduction in airway resistance with 4 puffs and 8 puffs. No difference in response between 2 chamber spacers

Significant reduction in airway resistance. No effect of tidal volume $8 \mathrm{~mL} / \mathrm{kg}$ versus $12 \mathrm{~mL} / \mathrm{kg}$ body weight

Significant reduction in airway resistance with both pMDI and nebulizer

Significant reduction in airway resistance with both pMDI and nebulizer for up to $2 \mathrm{~h}$ 
TABle 3. (CONTINUEd)

\begin{tabular}{|c|c|c|c|}
\hline $\begin{array}{l}\text { Author, year } \\
\text { (reference \#) }\end{array}$ & Drug (dose, mg) & Aerosol device & Response \\
\hline Mouloudi, $2000^{(89)}$ & $\begin{array}{l}\text { Albuterol (0.2, } \\
\quad 0.6 \mathrm{mg})\end{array}$ & pMDI-spacer & $\begin{array}{l}\text { Significant reduction in airway resistance. No effect of } \\
\text { decelerating flow pattern (pressure control) versus } \\
\text { square wave flow pattern (volume control) }\end{array}$ \\
\hline Mouloudi, 2001 & Albuterol $(0.6 \mathrm{mg})$ & pMDI-spacer & $\begin{array}{l}\text { Significant reduction in airway resistance for up to } 2 \mathrm{~h} \text {, } \\
\text { but the duration of effect was variable and } \\
\text { unpredictable in individual patients. }\end{array}$ \\
\hline Mouloudi, $2001^{(90)}$ & Albuterol $(0.4 \mathrm{mg})$ & pMDI-spacer & $\begin{array}{l}\text { Significant reduction in airway resistance. No effect of } \\
\text { inspiratory flow rate }(0.6 \mathrm{~L} / \mathrm{s} \text { versus } 1.2 \mathrm{~L} / \mathrm{s} \text { constant } \\
\text { flow, volume control ventilation })\end{array}$ \\
\hline Tzoufi, $2005^{91}$ & Albuterol (5 mg) & Nebulizer & $\begin{array}{l}\text { Significant reduction in airway resistance. Application } \\
\text { of external PEEP to counterbalance intrinsic PEEP } \\
\text { provided additional benefits }\end{array}$ \\
\hline Guerin, 2005 & Fenoterol (10 mg) & Nebulizer & $\begin{array}{l}\text { Application of external PEEP did not provide } \\
\text { additional benefits in reducing airway resistance or } \\
\text { lung hyperinflation. External PEEP levels may need } \\
\text { readjustment during treatment to prevent further } \\
\text { hyperinflation }\end{array}$ \\
\hline Malliotakis, $2007^{92}$ & Albuterol $(0.4 \mathrm{mg})$ & pMDI-spacer & $\begin{array}{l}\text { Significant reduction in airway resistance for up to } 2 \\
\text { hours, but there was no difference in the response } \\
\text { during volume control versus pressure support } \\
\text { ventilation with similar tidal volumes }\end{array}$ \\
\hline Malliotakis, $2008^{(93)}$ & $\begin{array}{l}\text { Salmeterol } \\
\text { (0.1 mg) }\end{array}$ & pMDI-spacer & $\begin{array}{l}\text { Significant reduction in airway resistance for up to } 8 \mathrm{~h} \text {, } \\
\text { but the duration of effect was variable and } \\
\text { unpredictable in individual patients. }\end{array}$ \\
\hline Kondili, 2011 ${ }^{(109)}$ & Albuterol $(0.4 \mathrm{mg})$ & pMDI-spacer & $\begin{array}{l}\text { Expiratory resistance of the respiratory system } \\
\text { (expiratory Rrs) was several-fold higher than } \\
\text { inspiratory resistance. After albuterol, there was } \\
\text { significant reduction in expiratory Rrs with increase } \\
\text { in the rate of lung emptying toward the end of } \\
\text { expiration. Changes in expiratory Rrs did not } \\
\text { correlate with changes in end-inspiratory inspiratory } \\
\text { resistance after albuterol }\end{array}$ \\
\hline
\end{tabular}

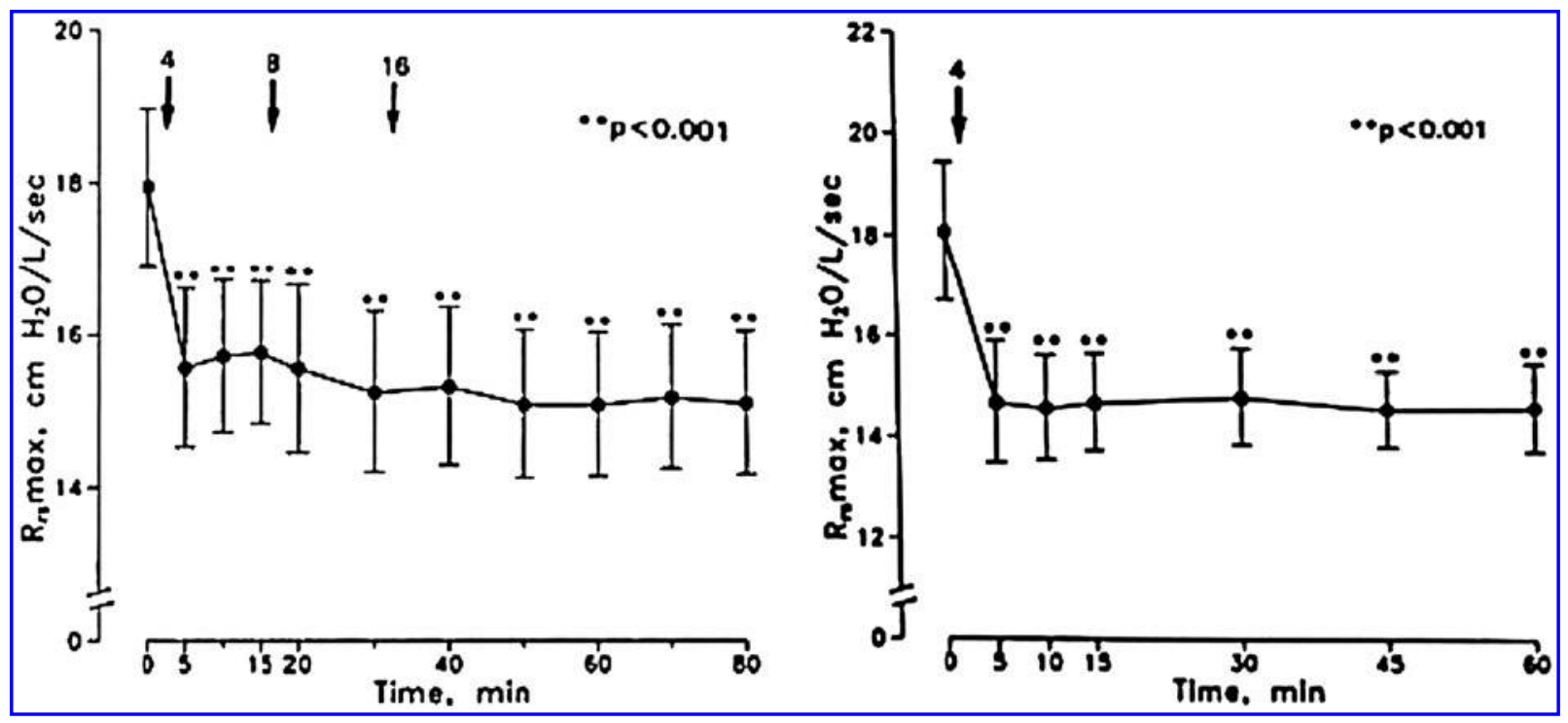

FIG. 2. Left panel: effect of albuterol on maximal inspiratory resistance (Rrs max) in 12 stable mechanically ventilated patients with COPD. Significant decreases in Rrs max occurred within 5 min of administration of four puffs of albuterol. The addition of 8 and 16 puffs (cumulative doses of 12 and 28 puffs, respectively) did not achieve a significantly greater effect than that with 4 puffs $(p>0.05)$. Right panel: the effect of four puffs of albuterol on Rrs max was confirmed in another group of seven stable mechanically ventilated patients with COPD. Significant reduction in Rrs max with four puffs of albuterol was sustained for $60 \mathrm{~min}$. Bars represent SE. ${ }^{* *} p<0.001$. (Reproduced with permission from Dhand et al.(29)) 
Table 4. Optimal Technique for Drug Delivery By PMDI in Ventilated Patients

1. Review order, identify patient, and assess need for bronchodilator.

2. Assess airway, remove excess secretions.

3. Shake pMDI and warm to hand temperature (prime if not used within $24 \mathrm{~h}$ ).

4. Place pMDI in adapter in ventilator circuit.

5. Remove HME. Do not disconnect humidifier.

6. Coordinate pMDI actuation with beginning of inspiration.

7. Wait at least $15 \mathrm{~s}$ between actuations; administer total dose.

8. Monitor for adverse response.

9. Reconnect HME.

10. Document clinical outcome.

pMDI, metered-dose inhaler; HME, heat and moisture exchanger.

additional costs of treatment, it is unclear if routine bronchodilator therapy in such a diverse group of patients confers any benefit in terms of improved clinical outcomes. ${ }^{(106)}$

\section{Assessment of the bronchodilator response}

The response to bronchodilators depends on several variables: patient airway geometry, degree of airway responsiveness, severity of disease, quantity and type of secretions, and counter regulatory effects of airway inflammation and other drugs. Most investigators assess response by measuring inspiratory airway resistance. Airway resistance in ventilated patients is commonly measured by performing rapid airway occlusions at constant flow inflation. ${ }^{(107,108)}$ This technique involves performing a breath-hold at endinspiration by occluding the expiratory port. Total or maxi-

Table 5. Optimal Technique for Drug Delivery by Jet Nebulizer in Ventilated Patients

1. Review order, identify patient, and assess need for bronchodilator.

2. Assess airway, remove excess secretions if present.

3. Place drug in nebulizer, do not exceed manufacturer recommendations

4. Place nebulizer in the inspiratory line 18 in $(46 \mathrm{~m})$ from the patient wye connector or proximal to the ventilator.

5. Use minimal flow-by or continuous flow during nebulizer operation.

6. Remove HME from circuit (do not disconnect humidifier).

7. Set gas flow to nebulizer at $2-10 \mathrm{~L} / \mathrm{min}$, based on manufacturer label.

a. Use ventilator to power nebulizer if it meets the nebulizer flow requirements and cycles on inspiration, or b. Use continuous flow from external source ( $\sim 50 \mathrm{psi})$.

8. Adjust ventilator volume or pressure limit and alarms to compensate for added flow.

9. Run until nebulizer begins to sputter.

10. Remove nebulizer from circuit, rinse with sterile water and run dry, store in safe place.

11. Reconnect humidifier or HME, return ventilator settings and alarms to previous values.

12. Monitor patient for adverse response.

13. Assess outcome and document findings.

HME, heat and moisture exchanger. mal inspiratory resistance ( $\operatorname{Rrs} \max$ ) can be partitioned into minimal inspiratory resistance (Rrs min), which reflects "ohmic" resistance of the airways, and additional effective resistance $(\Delta \mathrm{Rrs}) .^{(107,108)}$ Similarly, airway occlusion at endexpiration produces an increase in airway pressure to a plateau value, signifying intrinsic positive end expiratory pressure (PEEPi). ${ }^{(26)}$ Comparisons of airway resistance and intrinsic PEEP before and after drug administration are useful for assessing bronchodilator response.

Most ventilated patients with COPD demonstrate a decrease in airway resistance and intrinsic PEEP following bronchodilator administration (Table 3). That $\Delta$ Rrs does not decrease significantly after albuterol delivery with a pMDI, ${ }^{(26,29)}$ suggests that the bronchodilator effect occurs predominantly in the central airways with little effect on viscoelastic behavior or time-constant inhomogeneities in the lung. Moreover, albuterol does not significantly influence the elastic properties of the lung. ${ }^{(26)}$ In contrast, a greater decline in $\Delta$ Rrs was noted after nebulizer delivery of albuterol and ipratropium bromide. ${ }^{(86)}$ This difference in response between pMDIs and nebulizers could be explained by higher drug deposition in peripheral airways with a nebulizer.

Kondilli et al. ${ }^{(109)}$ measured expiratory resistance of the respiratory system (expiratory Rrs) in mechanically ventilated patients with COPD exacerbations. They found that albuterol significantly reduced expiratory Rrs, and enhanced the rate of lung emptying toward to the end of expiration. Interestingly, these investigators did not find any correlation between changes in expiratory Rrs and changes in endinspiratory resistance following albuterol administration. This discrepancy could be attributed to additional contributions by flow limitation and airway narrowing during expiration to the total expiratory resistance.

In bench models, drug delivery was increased during simulated spontaneous breaths compared to controlled mechanical breaths. ${ }^{(5)}$ However, in ventilated patients with acute exacerbations of COPD, the bronchodilator response did not differ between controlled mechanical ventilation and inspiratory pressure support ventilation. ${ }^{(92)}$ The use of propofol for sedation was a significant confounder of that study, ${ }^{(92)}$ because its bronchodilator effect ${ }^{(110)}$ may have influenced the response to albuterol during controlled mechanical ventilation.

\section{Drug toxicity}

Administration of high doses of $\beta$-adrenergic bronchodilators causes tachycardia, and has the potential to cause atrial and ventricular arrhythmias. ${ }^{(82)}$ In the recent ARDS Network study regular administration of nebulized albuterol produced a significant but modest increase in heart rate but did not result in an increased incidence of atrial fibrillation or ventricular arrhythmias. ${ }^{(106)}$

\section{Techniques of Administration}

The optimal techniques for administration of inhaled drugs to ventilated patients are based on the various factors discussed above. The technique employed may have to compromise between the optimum operating characteristics of the device and the patient's condition. For example, a higher duty cycle increases aerosol delivery, ${ }^{(5,67)}$ but it may worsen dynamic hyperinflation in patients with airflow 
limitation. ${ }^{(72)}$ With this caveat in mind, the technique of administration for pMDIs in ventilated patients is shown in Table 4 and that for nebulizers in Table 5. The key aspects of the technique with pMDIs are to place an appropriate adapter at a short distance $(\sim 15 \mathrm{~cm})$ from the endotracheal tube and to synchronize actuation with inspiratory flow. For nebulizers, it is critical to use the device as recommended by the manufacturer and to place it at a distance from the patient. When these techniques are employed, adequate pulmonary drug deposition is achieved ${ }^{(5,6,63)}$ and a significant bronchodilator response is observed (Table 3). However, most mechanically ventilated patients do not show incremental effects with higher drug doses of bronchodilators. ${ }^{(29)}$

Other classes of inhaled drugs may demonstrate linear dose-response relationships.

In summary, aerosol delivery in mechanically ventilated patients is complex. When meticulous attention is paid to the specific variables described above, it is possible to provide effective, reliable, consistent, and precise delivery of aerosols to the lungs of mechanically ventilated patients. When these factors are not carefully controlled and the optimum technique is not utilized, a greater proportion of the aerosol deposits in the ventilator circuit or artificial airways resulting in reduced efficiency of pulmonary drug delivery and the potential for ineffective therapy.

\section{Author Disclosure Statement}

Dr. Dhand and Dr. Ari have no conflict of interest with regard to this article. Dr. Fink is a consultant to the biotech industry and serves as scientific advisor to Aerogen, Ireland.

\section{References}

1. American Association for Respiratory Care: Aerosol consensus conference statement-1991. Respir Care. 1991;36:916-921.

2. MacIntyre NR, Silver RM, Miller CW, Schuler F, and Coleman RE: Aerosol delivery in intubated, mechanically ventilated patients. Crit Care Med. 1985;13:81-84.

3. Dhand R: Inhalation therapy with metered-dose inhalers and dry powder inhalers in mechanically ventilated patients. Respir Care. 2005;50:1331-1334.

4. Dhand R: Basic techniques for aerosol delivery during mechanical ventilation. Respir Care. 2004;49:611-622.

5. Fink J, Dhand R, Duarte A, Jenne J, and Tobin M: Aerosol delivery from a metered-dose inhaler during mechanical ventilation. An in-vitro model. Am J Respir Crit Care Med. 1996;154:382-387.

6. Fink JB, Dhand R, Grychowski J, Fahey PJ, and Tobin MJ: Reconciling in vitro and in vivo measurements of aerosol delivery from a metered-dose inhaler during mechanical ventilation and defining efficiency-enhancing factors. Am J Respir Crit Care Med. 1999;159:63-68.

7. Vecellio L, Guerin C, Grimbert D, De Monte M, and Diot P: In vitro study and semiempirical model for aerosol delivery control during mechanical ventilation. Intensive Care Med. 2005;31:871-876.

8. Dhand R, and Tobin MJ: Inhaled bronchodilator therapy in mechanically ventilated patients. Am J Respir Crit Care Med. 1997;156:3-10.

9. Dhand R: Nebulizers that use a vibrating mesh or plate with multiple apertures to generate aerosol. Respir Care. 2002;47:1406-1416.
10. Dolovich MB, and Dhand R: Aerosol drug delivery: developments in device design and clinical use. Lancet. 2011;377:1032-1045.

11. Laube BL, Janssens HM, de Jongh FH, Devadason SG, Dhand R, Diot P, Everard ML, Horvath I, Navalesi P, Voshaar T, Chrystyn H, European Respiratory Society, and International Society for Aerosols in Medicine: What the pulmonary specialist should know about the new inhalation therapies. Eur Respir J. 2011;37:1308-1331.

12. Georgopoulos D, Mouloudi E, Kondili E, and Klimathianaki M: Bronchodilator delivery with metered-dose inhaler during mechanical ventilation. Crit Care. 2000;4:227-234.

13. Ari A, Hess D, Myers TR, and Rau JL: A Guide to Aerosol Delivery Devices for Respiratory Therapists. American Association for Respiratory Care, Dallas, Texas; pp. 1-43, 2009.

14. Rau JL: The inhalation of drugs: advantages and problems. Respir Care. 2005;50:367-382.

15. Hess DR: Aerosol delivery devices in the treatment of asthma. Respir Care. 2008;53:699-723.

16. Rubin BK: Air and soul: the science and application of aerosol therapy. Respir Care. 2010;55:911-921.

17. Ari A, Areabi H, and Fink JB: Evaluation of position of aerosol device in two different ventilator circuits during mechanical ventilation. Respir Care. 2010;55:837-844.

18. Rau J, Harwood R, and Groff J: Evaluation of a reservoir device for metered-dose bronchodilator delivery to intubated adults: an in-vitro study. Chest. 1992;102:924-930.

19. Taylor RH, Lerman J, Chambers C, and Dolovich M: Dosing efficiency and particle-size characteristics of pressurized metered-dose inhaler aerosols in narrow catheters. Chest. 1993;103:920-924.

20. $\overline{\text { Diot } P,}$ Morra L, and Smaldone GC: Albuterol delivery in a model of mechanical ventilation. Comparison of metereddose inhaler and nebulizer efficiency. Am J Respir Crit Care Med. 1995;152(Pt 1):1391-1394.

21. Fuller HD, Dolovich MB, Posmituck G, Pack WW, and Newhouse MT. Pressurized aerosol versus jet aerosol delivery to mechanically ventilated patients. Comparison of dose to the lungs. Am Rev Respir Dis. 1990;141:440-444.

22. Alzahrani W, Harwood R, Fink J, Goodfellow L, and Ari A: Comparison of albuterol delivery during high frequency oscillatory ventilation and conventional mechanical ventilation of a simulated adult. Respiratory Care. 2010;55: 1576.

23. Branconnier M, and Hess D: Albuterol delivery during noninvasive ventilation. Respir Care. 2005;50:1649-1653.

24. Fink J: Metered-dose inhalers, dry powder inhalers and transitions. Respir Care. 2000;45:623-635.

25. Everard ML, Devadason SG, Summers QA, and Le Souef $\mathrm{PN}$ : Factors affecting total and "respirable" dose delivered by a salbutamol metered dose inhaler. Thorax. 1995;50:746749.

26. Dhand R, Jubran A, and Tobin MJ: Bronchodilator delivery by metered-dose inhaler in ventilator-supported patients. Am J Respir Crit Care Med. 1995;151:1827-1833.

27. Fuller HD, Dolovich MB, Turpie FH, and Newhouse MT: Efficiency of bronchodilator aerosol delivery to the lungs from the metered dose inhaler in mechanically ventilated patients. A study comparing four different actuator devices. Chest. 1994;105:214-218.

28. Rau J, Dunlevy C, and Hill R: A comparison of inline MDI actuators for delivery of a beta agonist and a corticosteroid with a mechanically-ventilated lung model. Respir Care. 1998;43:705-712. 
29. Dhand R, Duarte A, Jubran A, Jenne JW, Fink JB, Fahey PJ, and Tobin MJ: Dose response to bronchodilator delivered by metered-dose inhaler in ventilator supported patients. Am J Respir Crit Care Med. 1996;154:388-393.

30. O'Riordan TG, Greco MJ, Perry RJ, and Smaldone GC: Nebulizer function during mechanical ventilation. Am Rev Respir Dis. 1992;145:1117-1122.

31. Garner SS, Wiest DB, and Bradley JW: Albuterol delivery by metered-dose inhaler with a pediatric mechanical ventilatory circuit model. Pharmacotherapy. 1994;14:210 214.

32. Ari A, and Fink JB: Factors affecting bronchodilator delivery in mechanically ventilated adults. Nurs Crit Care. 2010;15:192-203.

33. Lange C, and Finlay W: Overcoming the adverse effect of humidity in aerosol delivery via pressurized metered-dose inhalers during mechanical ventilation. Am J Respir Crit Care Med. 2000;161:1614-1618.

34. Dhand R: New frontiers in aerosol delivery during mechanical ventilation. Respir Care. 2004;49:666-677.

35. Lin HL, Fink JB, Zhou Y, and Cheng YS: Influence of moisture accumulation in inline spacer on delivery of aerosol using metered-dose inhaler during mechanical ventilation. Respir Care. 2009;54:1336-1341.

36. Dhand R: Aerosol delivery during mechanical ventilation: from basic techniques to new devices. J Aerosol Med. 2008; 21:45-60.

37. Ari A, and Fink J: Aerosol drug delivery administration with helium-oxygen (heliox) mixtures: an overview. Curr Respir Med Rev. 2010;6:80-85.

38. Svartengren M, Anderson M, Philipson K, and Camner P: Human lung deposition of particles suspended in air or in helium/oxygen mixture. Exp Lung Res. 1989;15:575-585.

39. Goode ML, Fink JB, Dhand R, and Tobin MJ: Improvement in aerosol delivery with helium-oxygen mixtures during mechanical ventilation. Am J Respir Crit Care Med. 2001; 163:109-114.

40. Duarte AG: Inhaled bronchodilator administration during mechanical ventilation. Respir Care. 2004;49:623-634.

41. Hess DR, Acosta FL, Ritz RH, Kacmarek RM, Camargo CA Jr. The effect of heliox on nebulizer function using a betaagonist bronchodilator. Chest. 1999;115:184-189.

42. Tassaux D, Jolliet P, Thouret JM, Roeseler J, Dorne R, and Chevrolet JC: Calibration of seven ICU ventilators for mechanical ventilation with helium-oxygen mixtures. Am J Respir Crit Care Med. 1999;160:22-32.

43. Rau JL: Design principles of liquid nebulization devices currently in use. Respir Care. 2002;47:1257-1275.

44. Hess DR: Nebulizers: principles and performance. Respir Care. 2000;45:609-622.

45. Dhand R, and Sohal H: Pulmonary Drug Delivery System for inhalation therapy in mechanically ventilated patients. Expert Rev Med Devices. 2008;5:9-20.

46. Phipps P, and Gonda I: Droplets produced by medical nebulizers. Some factors affecting their size and solute concentration. Chest. 1990;97:1327-1332.

47. Steckel H, and Eskandar F: Factors affecting aerosol performance during nebulization with jet and ultrasonic nebulizers. Eur J Pharm Sci. 2003;19:443-455.

48. Watts $\mathrm{AB}, \mathrm{McC}$ conville JT, and Williams RO 3rd: Current therapies and technological advances in aqueous aerosol drug delivery. Drug Dev Ind Pharm. 2008;34:913-922.

49. Ruickbie S, Hall A, and Ball J: Therapeutic aerosols in mechanically ventiltated patients. In: J Vincent (ed). Annual
Update in Intensive Care and Emergency Medicine 2011. Springer, Berlin; pp. 197-206, 2011.

50. Perera AD, Kapitza C, Nosek L, Fishman RS, Shapiro DA, Heise T, and Heinemann L: Absorption and metabolic effect of inhaled insulin: intrapatient variability after inhalation via the Aerodose insulin inhaler in patients with type 2 diabetes. Diabetes Care. 2002;25:2276-2281.

51. Alvine GF, Rodgers P, Fitzsimmons KM, and Ahrens RC: Disposable jet nebulizers. How reliable are they? Chest. 1992;101:316-319.

52. Hess D, Fisher D, Williams P, Pooler S, and Kacmarek RM: Medication nebulizer performance. Effects of diluent volume, nebulizer flow, and nebulizer brand. Chest. 1996;110: 498-505.

53. Ari A, Atalay OT, Harwood R, Sheard MM, Aljamhan EA, and Fink JB: Influence of nebulizer type, position, and bias flow on aerosol drug delivery in simulated pediatric and adult lung models during mechanical ventilation. $\underline{\text { Respir }}$ Care. 2010;55:845-851.

54. Waldrep JC, and Dhand R: Advanced nebulizer designs employing vibrating mesh/aperture plate technologies for aerosol generation. Curr Drug Deliv. 2008;5:114-119.

55. Harvey C, O'Doherty M, Page C, Thomas S, Nunan T, and Treacher D: Comparison of jet and ultrasonic nebulizer pulmonary aerosol deposition during mechanical ventilation. Eur Respir J. 1997;10:905-909.

56. Pitance L, Vecellio L, Leal T, Reychler G, Reychler H, and Liistro G: Delivery efficacy of a vibrating mesh nebulizer and a jet nebulizer under different configurations. J Aerosol Med Pulm Drug Deliv. 2010;23:389-396.

57. Loffert DT, Ikle D, and Nelson HS: A comparison of commercial jet nebulizers. Chest. 1994;106:1788-1792.

58. Phillips G, and Millard F: The therapeutic use of ultrasonic nebulizers in acute asthma. Respir Med. 1994;88:387-389.

59. Thomas SH, O'Doherty MJ, Page CJ, Treacher DF, and Nunan TO: Delivery of ultrasonic nebulized aerosols to a lung model during mechanical ventilation. Am Rev Resp Dis. 1993;148:872-877.

60. Hughes J, and Saez J: Effects of nebulizer mode and position in a mechanical ventilator circuit on dose efficiency. Respir Care. 1987;32:1131-1135.

61. O'Doherty MJ, Thomas SH, Page CJ, Treacher DF, and Nunan TO: Delivery of a nebulized aerosol to a lung model during mechanical ventilation. Effect of ventilator settings and nebulizer type, position, and volume of fill. Am Rev Respir Dis. 1992;146:383-388.

62. Moraine J, Truflandier K, Vandenbergen N, Berre J, Melot $\mathrm{C}$, and Vincent J: Placement of the nebulizer before the humidifier during mechanical ventilation: effect on aerosol delivery. Heart Lung. 2009;38:435-439.

63. Miller DD, Amin MM, Palmer LB, Shah AR, and Smaldone GC: Aerosol delivery and modern mechanical ventilation: in vitro/in vivo evaluation. Am J Respir Crit Care Med. 2003;168:1205-1209.

64. Dhand R: Aerosol therapy during mechanical ventilation: getting ready for prime time. Am J Respir Crit Care Med. 2003;168:1148-1149.

65. Dhand R, and Guntur VP: How best to deliver aerosol medications to mechanically ventilated patients. Clin Chest Med. 2008;29:277-296.

66. Dellweg D, Wachtel H, Hohn E, Pieper MP, Barchfeld T, Köhler D, and Glaab T: In vitro validation of a respimat ${ }^{\circledR}$ adapter for delivery of inhaled bronchodilators during mechanical ventilation. J Aerosol Med. 2011;24:285-292. 
67. O'Riordan TG, Palmer LB, and Smaldone GC: Aerosol deposition in mechanically ventilated patients. Optimizing nebulizer delivery. Am J Respir Crit Care Med. 1994;149: 214-219.

68. Newman S, Pavia D, Moren F, Sheahan N, and Clarke SW: Deposition of pressurised aerosols in the human respiratory tract. Thorax. 1981;36:52-55.

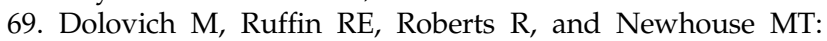
Optimal delivery of aerosols from metered dose inhalers. Chest. 1981;80(Suppl 6):911-915.

70. Duarte A, Dhand R, Reid D, Tobin M, and Jenne J: Serum salbutamol levels after metered-dose inhaler administration to ventilated patients and healthy controls. Am J Respir Crit Care Med. 1996;154:1658-1663.

71. Marik P, Hogan J, and Krikorian J: A comparison of bronchodilator therapy delivered by nebulization and metered-dose inhaler in mechanically ventilated patients. Chest. 1999;115:1653-1657.

72. Guerin C, Fassier T, Bayle F, Lemasson S, and Richard J: Inhaled bronchodilator administration during mechanical ventilation: How to optimize it and for which clinical benefit? J Aerosol Med. 2008;21:85-95.

73. Boucher RC: Evidence for airway surface dehydration as the initiating event in CF airway disease. I Intern Med. 2007;261:5-16.

74. Fresoli RP, Smith RM Jr, Young JA, and Gottshall SC: Use of aerosol isoproterenol in an anesthesia circuit. Anesth Analg. 1968;47:127-132.

75. Gold MI: Treatment of bronchospasm during anesthesia. Anesth Analg. 1975;54:783-786.

76. Gay PC, Rodarte JR, Tayyab M, and Hubmayr RD: Evaluation of bronchodilator responsiveness in mechanically ventilated patients. Am Rev Respir Dis. 1987;136:880-885.

77. Wegener T, Wretman S, Sandhagen B, and Nystrom SO: Effect of ipratropium bromide aerosol on respiratory function in patients under ventilator treatment. Acta Anaesthesiol Scand. 1987;31:652-654.

78. Bernasconi M, Brandolese R, Poggi R, Manzin E, and Rossi A: Dose-response effects and time course of effects of inhaled fenoterol on respiratory mechanics and arterial oxygen tension in mechanically ventilated patients with chronic airflow obstruction. Intensive Care Med. 1990;16: 108-114.

79. Fernandez A, Lazaro A, Garcia A, Aragon C, and Cerda E: Bronchodilators in patients with chronic obstructive pulmonary disease on mechanical ventilation. Utilization of metered-dose inhalers. Am Rev Respir Dis. 1990;141:164168.

80. Gay PC, Patel HG, Nelson SB, Gilles B, and Hubmayr RD: Metered dose inhalers for bronchodilator delivery in intubated, mechanically ventilated patients. Chest. 1991;99: 66-71.

81. Mancebo J, Amaro P, Lorino H, Lemaire F, Harf A, and Brochard L: Effects of albuterol inhalation on the work of breathing during weaning from mechanical ventilation. Am Rev Respir Dis. 1991;144:95-100.

82. Manthous C, Hall C, Schmidt G, and Wood L: Metereddose inhaler versus nebulized salbutamol in mechanically ventilated patients. Am Rev Resp Dis. 1993;148:1567-1570.

83. Yang SC, Yang SP, and Lee TS: Nebulized ipratropium bromide in ventilator-assisted patients with chronic bronchitis. Chest. 1994;105:1511-1515.

84. Mouloudi E, Katsanoulas K, Anastasaki M, Askitopoulou E, and Georgopoulos D: Bronchodilator delivery by me- tered-dose inhaler in mechanically ventilated COPD patients: influence of end-inspiratory pause. Eur Respir J. 1998;12:165-169.

85. Waugh JB, Jones DF, Aranson R, and Honig EG: Bronchodilator response with use of OptiVent versus Aerosol Cloud Enhancer metered-dose inhaler spacers in patients receiving ventilatory assistance. Heart Lung. 1998;27:418423.

86. Guerin C, Chevre A, Dessirier P, Poncet T, Becquemin MH, Dequin PF, Le Guellec C, Jacques D, and Fournier G: Inhaled fenoterol-ipratropium bromide in mechanically ventilated patients with chronic obstructive pulmonary disease. Am J Respir Crit Care Med. 1999;159(Pt 1):10361042.

87. Mouloudi E, Katsanoulas K, Anastasaki M, Hoing S, and Georgopoulos D: Bronchodilator delivery by metered-dose inhaler in mechanically ventilated COPD patients: influence of tidal volume. Intensive Care Med. 1999;25:1215-1221.

88. Duarte A, Momi K, and Bidani A: Bronchodilator therapy with metered dose inhaler and spacer versus nebulizer in mechanically ventilated patients: comparison of magnitude and duration of response. Respir Care. 2000;45:817823.

89. Mouloudi E, Prinianakis G, Kondili E, and Georgopoulos D: Bronchodilator delivery by metered-dose inhaler in mechanically ventilated COPD patients: influence of flow pattern. Eur Respir J. 2000;16:263-268.

90. Mouloudi E, Maliotakis C, and Kondili E: Duration of salbutamol-induced bronchodilation delivered by metereddose inhaler in mechanically ventilated COPD patients. Monaldi Arch Chest Dis. 2001;56:189-194.

91. Tzoufi M, Mentzelopoulos SD, Roussos C, and Armaganidis A: The effects of nebulized salbutamol, external positive end-expiratory pressure, and their combination on respiratory mechanics, hemodynamics, and gas exchange in mechanically ventilated chronic obstructive pulmonary disease patients. Anesth Analg. 2005;101:843-850.

92. Malliotakis P, Mouloudi E, Prinianakis G, Kondili E, and Georgopoulos D: Influence of respiratory efforts on b2-agonist induced bronchodilation in mechanically ventilated COPD patients: a prospective clinical study. Respir Med. 2007;101:300-307.

93. Malliotakis P, Linardakis M, Gavriilidis G, and Georgopoulos D: Duration of salmeterol-induced bronchodilation in mechanically ventilated chronic obstructive pulmonary disease patients: a prospective clinical study. Crit Care. 2008;12:R140.

94. Fernandez A, Munoz J, de la Calle B, Alia I, Ezpeleta A, de la Cal MA, and Reyes A: Comparison of one versus two bronchodilators in ventilated COPD patients. Intensive Care Med. 1994;20:199-202.

95. Rabe KF, Atienza T, Magyar P, Larsson P, Jorup C, and Lalloo UG: Effect of budesonide in combination with formoterol for reliever therapy in asthma exacerbations: a randomised controlled, double-blind study. Lancet. 2006; 368:744-753.

96. Nava S, and Compagnoni ML: Controlled short-term trial of fluticasone propionate in ventilator-dependent patients with COPD. Chest. 2000;118:990-999.

97. Rodrigo GJ: Rapid effects of inhaled corticosteroids in acute asthma: an evidence-based evaluation. Chest. 2006;130: 1301-1311.

98. Morice AH, Morris D, and Lawson-Matthew P: A comparison of nebulized budesonide with oral prednisolone in 
the treatment of exacerbations of obstructive pulmonary disease. Clin Pharmacol Ther. 1996;60:675-678.

99. Maltais F, Ostinelli J, Bourbeau J, Tonnel AB, Jacquemet $\mathrm{N}$, Haddon J, Rouleau M, Boukhana M, Martinot JB, and Duroux P: Comparison of nebulized budesonide and oral prednisolone with placebo in the treatment of acute exacerbations of chronic obstructive pulmonary disease: a randomized controlled trial. Am J Respir Crit Care Med. 2002;165:698-703.

100. Mirici A, and Akgun M: Comparison of the efficacy of nebulized budesonide with parenteral corticosteroids in the treatment of acute exacerbations of chronic obstructive pulmonary disease. Clin Drug Invest. 2003;23:55-62.

101. Ernst P, Gonzalez A, Brassard P, and Suissa S: Inhaled corticosteroid use in chronic obstructive pulmonary disease and the risk of hospitalization for pneumonia. Am J Respir Crit Care Med. 2007;176:162-166.

102. Guerin C, Durand PG, Pereira C, Richard JC, Poupelin JC, Lemasson S, Badet M, Philit F, Vecellio L, and Chantrel G: Effects of inhaled fenoterol and positive end-expiratory pressure on the respiratory mechanics of patients with chronic obstructive pulmonary disease. Can Respir J. 2005; 12:329-335.

103. Dhand R, and Tobin MJ: Bronchodilator delivery with metered-dose inhalers in mechanically-ventilated patients. Eur Respir J. 1996;9:585-595.

104. Wright P, Carmichael L, and Bernard G: Effect of bronchodilators on lung mechanics in the acute respiratory distress syndrome (ARDS). Chest. 1994;106:1517-1523.

105. Morina P, Herrera M, Venegas J, Mora D, Rodriguez M, and Pino E: Effects of nebulized salbutamol on respiratory mechanics in adult respiratory distress syndrome. Intensive Care Med. 1997;23:58-64.

106. The National Heart, Lung, and Blood Institute Acute Respiratory Distress Syndrome (ARDS) clinical trials network: Randomized, placebo-controlled clinical trial of an aerosolized beta-2 agonist for treatment of acute lung injury. Am J Respir Crit Care Med. 2011;184:567-568.
107. Bates J, Rossi A, and Milic-Emili J: Analysis of the behavior of the respiratory system with constant inspiratory flow. J Appl Physiol. 1985;58:1840-1848.

108. Bates J, and Milic-Emili J: The flow interruption technique for measuring respiratory resistance. J Crit Care. 1991;6: 227-238.

109. Kondili E, Alexopoulou C, Prinianakis G, Xirouchaki N, Vaporidi K, and Georgopoulos D: Effect of albuterol on expiratory resistance in mechanically ventilated patients. Respir Care. 2011;56:626-632.

110. Conti G, Dell'Utri D, Vilardi V, De Blasi RA, Pelaia P, Antonelli M, Bufi M, Rosa G, and Gasparetto A: Propofol induces bronchodilation in mechanically ventilated chronic obstructive pulmonary disease (COPD) patients. Acta Anaesthesiol Scand. 1993;37:105-109.

111. Mouloudi E, Prinianakis G, Kondili E, and Georgopoulos D: Effect of inspiratory flow rate on beta2-agonist induced bronchodilation in mechanically ventilated COPD patients. Intensive Care Med. 2001;27:42-46.

Received on October 12, 2011 in final form, November 17, 2011

Reviewed by: Timothy Corcoran

Address correspondence to: Rajiv Dhand, M.D. Professor and Chairman Department of Medicine University of Tennessee Graduate School of Medicine 1924 Alcoa Highway, U114 Knoxville, TN 37920

E-mail: RDhand@mc.utmck.edu 